EMBRYARIDDLE
Aeronautical University

SCHOLARLY COMMONS
International Journal of Aviation, Aeronautics, and Aerospace

2-16-2016

\title{
Commercial Aircraft Electronic Checklists: Benefits and Challenges (Literature Review)
}

Paul L. Myers III

Embry-Riddle Aeronautical University, myersiip@erau.edu

Follow this and additional works at: https://commons.erau.edu/ijaaa

Part of the Cognition and Perception Commons

\section{Scholarly Commons Citation}

Myers, P. L. (2016). Commercial Aircraft Electronic Checklists: Benefits and Challenges (Literature Review). International Journal of Aviation, Aeronautics, and Aerospace, 3(1). https://doi.org/10.15394/ ijaaa.2016.1112

This Literature Review is brought to you for free and open access by the Journals at Scholarly Commons. It has been accepted for inclusion in International Journal of Aviation, Aeronautics, and Aerospace by an authorized administrator of Scholarly Commons. For more information, please contact commons@erau.edu. 


\section{Background}

\section{Why checklists?}

Checklists were not needed in the early days of aviation due to aircraft simplicity. On October 30, 1935, that changed. A model 299 aircraft, later to be designated the B-17, crashed shortly after takeoff because the pilots failed to release a new rudder and elevator locking mechanism (Schultz, 2012). After that, checklists became standard issue in aircraft, but as aircraft became more complicated, more checklist errors surfaced. The Federal Aviation Administration (FAA) (1995) using National Transportation Safety Board (NTSB) data, identified improper checklist usage as either a probable cause or contributing factor in 37 major accidents between 1978 and 1990. Additionally, a safety analysis branch of the FAA in the same study concluded that between 1983 and 1993, 279 accidents involving checklist errors accounted for 215 fatalities and 260 plus injuries. The highest percentage of checklist related mishaps occurred during the pre-departure or departure phases of flight (FAA, 1995). Two examples of these types of errors are confirmed in the NTSB accident reports for Northwest Flight 255 in 1987 and Delta Flight 1141 in 1989.

Checklist error mishap examples. Two airline mishaps, Northwest Flight 255, a DC-9 leaving Detroit and Delta Flight 1141, a 727 leaving Dallas/Ft Worth, crashed shortly after takeoff. The primary cause of both mishaps was checklist error resulting in the total deaths of 170 people (NTSB, 1987; NTSB 1989).

Development of electronic checklists (ECL). Boeing started the process of studying ECLs in the late 1980s. ECL development continued from 1990 to 1996 until the ECL was certified and introduced on the Boeing 777 in response to documented checklist errors, a year after the FAA report was released. The 777 ECL included all normal and non-normal checklists required for safe operations (Arkell, 2006). The Boeing ECL can also be linked to the Engine Indicating and Crew Alerting System (EICAS) (Boorman, 2001a). The Airbus ECL derivative is called the Electronic Centralized Aircraft Monitoring (ECAM) system and like the Boeing ECL includes normal and non-normal procedures for the Airbus 320, 330 and 340 families (Airbus, 2015; Phoenix Software Solutions, 2002).

Boorman (2001a) describe three levels of ECLs that were postulated for a Boeing aircraft accident study and do not formally exist, but can be used to fundamentally describe three basic levels of ECL automation. Variant 1 is nonintegrated with the aircraft. Variant 2 is integrated with the airplane so the aircraft has the capability to know switch positions to verify checklist completion and is 
smart enough to display the correct checklist at the appropriate time. Variant 3 is integrated and similar to Variant 2, but adds the capability to automatically alert pilots when checklists have not been completed in critical phases of flight.

\section{Practice Innovation}

While electronic checklists were first introduced in 1996, they are everchanging. Therefore, to provide updated information, electronic checklist benefits and challenges are examined in practical and human factors terms and recommendations developed to chart future ECL development.

\section{Benefits}

Improves information processing and reduces workload. Information processing requirements increased significantly as more technology was integrated into aircraft. Coupled with that, humans have a limited short-term memory linked to the ability to chunk information (Vidulich, Wickens, Tsang \& Flach, 2010). ECLs, as automation tools, are designed to make information processing easier. Degani and Wiener (1993) in their checklist design study support this concept advocating that checklists are designed to prevent reliance on the pilot's short and long-term memory thereby reducing mental workload. A major function of the ECL is to make aircraft systems information gathering easier, enhancing situational awareness (Snead, Militello \& Ritter, 2004).

Reduces errors. Reason, as cited by Vidulich et al. (2010), summarized that errors are inevitable and are an acceptable price human beings must pay for their ability to cope with very difficult informational tasks. ECLs, an element of automation, are designed to keep track of open and completed checklist items and reduce errors. Fundamentally, the Boeing ECL is designed to reduce the errors listed in Table 1 (Boorman, 2001b). In an unpublished simulator study, Boeing found a $46 \%$ decrease in errors compared to paper checklists (Boorman, 2000). Additionally, in a separate Boeing study of aircraft accidents from 1978 to 2001, it was found that with variant 3,19 accidents could have been prevented (Boorman, 2001a). Snead, Militello, and Ritter (2004) verified Boorman's opinion stating that since ECLs have been used, there has been a reduction in the number of errors. To help reduce errors, the Boeing electronic checklist requires pilots to accomplish the checklist steps in sequence, with some steps tied to aircraft sensors to not allow the pilot to bypass the step until the step has been completed. This is known as a closed loop checklist item, essentially an intelligent aircraft checking the human (FAA, 1996). By not allowing the pilots to progress further in the checklist process until the step is completed, errors are reduced. For non-normal checklists, the course of 
action is suggested along with consequences of failing to act appropriately (Arkell, 2006). Palmer and Degani (1991) generalize checklist errors into four consolidated categories as reduction targets: (1) forgetting what the current item is and thereby inadvertently skipping the item; (2) skipping items due to interruptions and distractions; (3) intentionally skipping an item and then forgetting to return to it; and (4) stating that an item has been accomplished when it was not.

Table 1

Boorman (2001b) Paper Checklist Error Modes

\begin{tabular}{|l|}
\hline PAPER CHECKLIST ERROR MODE \\
\hline Both Normal and Non-Normal Checklists \\
\hline Skipped items \\
\hline Place lost in checklist when crew becomes distracted \\
\hline $\begin{array}{l}\text { Excessive workload due to holding/turning/marking checklist } \\
\text { pages, recovering dropped checklists }\end{array}$ \\
\hline Incorrect switch is selected \\
\hline Checklist is misread or unreadable due to poor illumination \\
\hline Normal Checklists (NC) Only \\
\hline NC step is skipped \\
\hline NC is not initiated \\
\hline Non-normal Checklists (NNC) Only \\
\hline Incorrect NNC is accomplished \\
\hline NNC is skipped or left incomplete \\
\hline Incorrect steps accomplished in checklist branching \\
\hline Steps required later in flight are not accomplished \\
\hline $\begin{array}{l}\text { Operational notes or revised limitations following malfunction } \\
\text { are forgotten }\end{array}$ \\
\hline $\begin{array}{l}\text { Wrong steps accomplished when multiple related } \\
\text { failures have conflicting or redundant actions }\end{array}$ \\
\hline $\begin{array}{l}\text { Excessive cognitive workload in multiple failure } \\
\text { case leads to omitted NNC or other errors }\end{array}$ \\
\hline
\end{tabular}

Can improve response time. Sharno, Dror and Degani (1998) in a study using 20 Boeing 747 crewmembers compared electronic to paper media in the performance of information search and performance calculation problems. They found that electronic media outperformed paper media 1.3 to 1 in terms of correct responses and response time was twice as fast. While reducing errors are the 
primary ECL focus, improved efficiency in task demanding situations is a desired by-product (D. Boorman, personal communication, October 31, 2015).

\section{Challenges}

Unexpected situations. An inherent problem with electronic, like paper, checklists is the inability to cover all non-normal situations a crew might encounter (Snead et al., 2004). No checklist is perfect; hence unique situations can occur requiring pilot experience and judgment to solve the problem.

May not identify larger scope problems. The B-2 Multiple Display Unit (MDU) displays multiple advisory, caution and warning lights and parallels commercial aircraft applications. While the MDU is a good tool for providing information about individual warning lights, it lacks the ability to associate the warning lights together to identify a larger problem that exists (Snead et al., 2004). In this case, it is up to the pilot to make that decision relying on experience and systems knowledge.

Keyhole property. The keyhole property occurs when pilots forget where to find needed information or get lost in the complexity of menus. To alleviate this, checklist menus need to be planned and displayed properly (Mallis, Banks \& Dinges, 2010).

Errors can still occur. While the number of errors have been reduced, human error still can and most likely will occur. In a study of 135 procedural errors, 10 paper/ECL checklist errors were noted equating to error rate of 7.4\% (Sharno et al., 1998). One fundamental error that might occur with glass cockpit displays, such as the electronic checklist, is an "out of sight, out of mind" phenomenon where pilots have tunneled attention and forget or ignore information outside of the current focus (Mallis et al. 2010, p. 450). This tunneling effect can occur when focused on the electronic checklist, the paper checklist, or on another issue in the cockpit, degrading situational awareness.

Added costs. ECLs are incorporated in new aircraft such as the Boeing 787, and the user can have the checklists modified, but not without added expense to the airlines. Additionally, FAA Advisory Circular 120-64 levies certification, training, and currency requirements and stipulates that paper checklists with the same content be carried at all times in the aircraft (FAA, 1996). Training, software upgrades, and component maintenance are also added costs. 
Not on all aircraft. Variant 3 electronic normal and non-normal checklists are incorporated on later Boeing aircraft such as 777, 787 and 747-800. Later Airbus aircraft; 320, 330 and 340, incorporate ECLs for normal procedures, and nonnormal procedures. Additionally, Boeing has also integrated an iPad based checklist system, often called the Electronic Flight Bag (EFB) on non-ECL aircraft. One drawback of the iPad type checklist is the non-integration aspect of not being able to monitor aircraft systems. Due to non-integration, open loop checklist items may occur when the airplane has no way of checking itself to see if the checklist item was completed, therefore preventing crew feedback if an error occurs (Boorman, 2001a). The EFB also presents additional FAA requirements listed in Advisory Circular 120-76C that must be complied with (FAA, 2014).

Paper checklists are still required. The FAA requires paper checklists even when the aircraft has ECLs (FAA, 1996). The fundamental difference between Boeing and Airbus ECLs is that the Boeing version is a user-modifiable checklist system while the Airbus checklist is not. Having a modifiable checklist improves operational flexibility. In Boeing aircraft, paper checklists are carried in case of system failure, since both paper and electronic checklists have the same items (D. Boorman, personal communication, October 31, 2015). For some Airbus ECLs, all non-normal situations are not covered and/or incomplete and therefore require paper checklists to supplement or replace the electronic procedures (Scribd, 2015). In this case, the ECL provides for safety of flight items only, but there are no checklist flows for non-normal procedures. Having to go back and forth between paper and electronic checklists increases cognitive workload and potential errors. A modifiable checklist eliminates these issues. According to Dr. John Sabel, an Embry-Riddle Aviation University Assistant Professor, and airline Captain with 18,000 hours of flying time, incompleteness of ECLs can also be due to untimely software upgrades to non-modifiable electronic checklists (Personal communication, August 30, 2015). Dr. Sabel's assertion is supported by a lengthy detailed upgrade process without time constraints that are listed in FAA Advisory Circular 120-64 (FAA, 2006). Finally, electrical failures may render the ECL screen unusable and therefore, paper checklists provide redundancy (NTSB, 2008).

Automation dependency. ECLs can aid human information processing by monitoring checklist completion and aircraft systems. It cannot be assumed, however, that the system provides accurate redundancy to human monitoring. Too much dependency on automation of electronic checklists can result in a loss of pilot situational awareness (Palmer \& Degani, 1991). The FAA supports this by advocating in Advisory Circular 120-64 that some checklist item callouts "may be necessary to ensure total crew awareness or airplane status" (FAA, 1996, p. 8). 
Frequency of use dichotomy. Pilots must maintain an active not passive involvement using ECLs, because loss of situational awareness (SA) can still be a problem. A potential new ECL error related to SA is "frequency of use dichotomy" which can occur when something such as a non-normal procedure is not used very often and when used under high workload stress conditions presents difficulties (Boorman, 2000, p. 2)

Passive operator involvement. When pilots are performing monitoring and are not actively involved, monitoring performance can decline. Additionally, too much system trust can degrade effective monitoring capability. If SA is lost, being responsive when automation fails is unlikely (Moulova, Hancock, Jones \& Vincenzi, 2010).

\section{Conclusions and Recommendations}

ECLs have had a significant impact reducing normal and to some extent, nonnormal checklist execution errors. For normal checklist items, if integrated with the aircraft, ECLs eliminate or reduce many of the paper checklist error modes by using closed loop checklist processing enhancing safety. Additionally, ECLs make it easier to gather information about aircraft systems enhancing information processing, reducing mental workload and enhancing situational awareness. Unfortunately, many older aircraft do not incorporate normal procedures electronic checklists. In these cases, the EFB / iPad checklist provides a workable, but nonoptimum solution since the device is not integrated with the aircraft.

For non-normal procedures, several obstacles remain. First, ECLs bring more potential error modes including automation dependency, the keyhole effect, monitoring complacency, out of sight and out of mind, and the potential for increased frequency of use dichotomy. Second, the future path of technology needs to be defined. Like paper checklists, the machine cannot be programmed for all possible non-normal situations and in many cases cannot yet reason a larger problem when multiple alerts are present.

Concurrently with defining the future path, electronic checklists levels of automation need to be standardized both in industry and FAA using the Boeing variant levels and incorporating a fourth level of automation for no electronic checklist capability. The proposed levels are illustrated in Table 2. 
Table 2

Proposed Electronic Checklist Levels of Automation

\begin{tabular}{|lll|}
\hline $\begin{array}{l}\text { Level of } \\
\text { Automation }\end{array}$ & Level Description & Example System \\
\hline Level 0 & $\begin{array}{l}\text { No electronic checklist } \\
\text { on aircraft }\end{array}$ & None. \\
\hline Level 1 & $\begin{array}{l}\text { Electronic checklist not } \\
\text { integrated with aircraft. }\end{array}$ & $\begin{array}{l}\text { Electronic flight } \\
\text { bag. }\end{array}$ \\
\hline Level 2 & $\begin{array}{l}\text { Electronic checklist } \\
\text { integrated with aircraft } \\
\text { and aircraft has the } \\
\text { ability to verify some or } \\
\text { all checklist items } \\
\text { complete }\end{array}$ & $\begin{array}{l}\text { Electronic checklist } \\
\text { on an Airbus 330. }\end{array}$ \\
& $\begin{array}{l}\text { Electronic checklist } \\
\text { integrated with aircraft, } \\
\text { aircraft has the ability to } \\
\text { verify some or all } \\
\text { checklist items complete } \\
\text { and aircraft has the } \\
\text { ability to self-identify } \\
\text { checklist errors without } \\
\text { operator interaction. }\end{array}$ & $\begin{array}{l}\text { On Boeing } 777 \text { and } \\
\text { electronic }\end{array}$ \\
& \\
&
\end{tabular}

Using the proposed levels of automation, level 3 is the highest variant that currently exists. However, an important consideration is the next ECL automation level. To move ECL development forward, automation level goals should be set as a team effort between aircraft manufacturers, FAA, NASA and airlines. Also, to reduce cognitive workload and error potential, the ECL standard needs to be a modifiable checklist. If the decision is to retain non-modifiable checklists, the lengthy ECL upgrade time needs to be examined and streamlined by the FAA in concert with the airlines.

While it may seem the challenges outweigh the benefits, ECL research needs to continue to reap safety benefits of reducing and/or eliminating errors. As recently as 2014, 30\% of Aviation Safety Reporting System (ASRS) checklist incidents listed were pilot induced (NASA, 2015). Preventing even one mishap such as Northwest Flight 255 or Delta Flight 1141 is worth the effort in lives saved. 


\section{References}

Airbus. (2015). Flight operations briefing notes standard operating procedures normal checklists. Retrieved from http://www.airbus.com/fileadmin/media _gallery/files_safety_library_items/AirbusSafetyLib_-FLT_OPS_SOP_ SEQ05.pdf

Arkell, D. (2006). Boeing's electronic checklist marks 10 years of enhanced safety for pilots and travelers. Boeing Frontiers, 04, 11. Retrieved from http://www.boeing.com/news/frontiers/archive/2006/april/i_ca3html

Boorman, D. (2000). Reducing flight crew errors and minimizing new error modes with electronic checklists. In the Proceedings of the International Conference on Human- Computer Interaction in Aeronautics, 2000. Toulouse, France: Polytechnic International Press.

.Boorman, D. (2001a). Safety benefits of electronic checklists - An analysis of commercial transport accidents. Proceedings of the 11th International Symposium on Aviation Psychology, 1-6; Columbus, OH: The Ohio State University.

Boorman, D. (2001b). Today's electronic checklists reduce likelihood of crew errors and help prevent mishaps. ICAO Journal, 56, 17-20, 36. Montreal, Canada: ICAO.

Degani, A., \& Wiener, E. (1993). Cockpit checklists - concepts, design, and use. Human Factors and Ergonomics Proceedings, 35(2), 345-359. Santa Monica, CA: Human Factors and Ergonomics Society.

Federal Aviation Administration. (2014). Guidelines for the Certification, Airworthiness, and Operational Use of Electronic Flight Bags (Advisory Circular 120-76C). Washington, D.C.: U.S. Department of Transportation. Retrieved from http://www.faa.gov/Regulations_policies/advisory_ circulars/index.cfm/go/Document.information/documentID/1024366

Federal Aviation Administration. (1996). Operational use and modification of electronic checklists (Advisory Circular 120-64). Washington, D.C.: U.S. Department of Transportation. Retrieved from http ://www.faagov/regulations_policies/advisory_cirular/ind ex.cfm/go/document.information/documentID/23204 
Federal Aviation Administration. (1995). Human performance considerations in the use and design of aircraft checklists. Washington, D.C.: U.S. Department of Transportation. Retrieved from http://www.skybrary. aero/bookshelf/books/1566.pdf

Mallis, M., Banks, S., \& Dinges, D. F. (2010). Aircrew fatigue; sleep need and circadian rhythmicity. In E. Salas \& D. Maurino (Eds.), Human factors in aviation (2nd ed.) (pp. 401- 436). Burlington, MA: Academic Press Elsevier.

Moulova, M., Hancock, P., Jones, L, \& Vincenzi, D. (2010). Automation in aviation systems: issues and Considerations. In J. Wise, D. Hopkin, D. Garland (Eds.) Handbook of aviation human factors (2nd ed.) (pp 8-18-11). Boca Raton, FL: CDC Press.

National Aeronautics and Space Administration. (2015). ASRS database report set checklist incidents. Retrieved From http://asrs.arc.nasa.gov/docs/rpsts/ chklist.pdf

National Transportation Safety Board. (1987). Northwest Airlines, McDonnell Douglas DC-9, N312RC. Detroit Metropolitan Wayne County Airport, Romulus Michigan August 16, 1987 (Aircraft accident report, NTSB/AAR88-05). Washington, D.C.: Author.

National Transportation Safety Board. (1989). Delta Air Lines, Boeing 727-232, N473DA. Dallas-Fort Worth International Airport, Texas. August 31, 1988 (Aircraft accident report, NTSB/AAR-89/04). Washington, DC.: Author.

National Transportation Safety Board. (2008). NTSB urges fixes to Airbus cockpit displays. Air Safety Week, 22, 31.

Palmer, E.A., \& Degani, A. (1991). Electronic checklists - evaluation of two levels of automation. Proceedings of the Sixth International Symposium on Aviation Psychology (pp. 178-183). Columbus, OH: The Ohio State University. 
Phoenix Software Solutions. (2002). Airbus aircraft operating manual. Retrieved from http://www.slideshare.net/alkhaldy/70/airbus-a320-aircraftoperation-manual

Schultz, T. P. (2012). Where did checklists come from? Retrieved from http://www.acc.af.mil/news/story.asp?id=123292972

Scribd. (2015). A320 guidelines for training. Retrieved from http://www.scribd. com/doc/123786504/A320-Guidelines-for-Training-pdf

Shamo, M. K., Dror, R., \& Degani, A. (1998). Evaluation of a new cockpit device: the integrated electronic information system. Proceedings of the Human Factors and Ergonomics Society Annual Meeting, 42(1), 138-142.

Snead, A. E, Militello, L. G., \& Ritter, J. A. (2004). Electronic checklists in the context of B-2 pilot decision making. Proceedings of the Human Factors and Ergonomics Society Annual Meeting, 48, 640-644.

Vidulich, M. A., Wickens, C. D., Tsang, P. S., \& Flach, J. M. (2010). Information processing in aviation. In E. Salas \& D. Maurino (Eds.), Human factors in aviation (2nd ed.) (pp. 175-215). Burlington, MA: Academic Press - Elsevier. 